\title{
PELAKSANAAN KEGIATAN HYPNOBREASTFEEDING PADA IBU MENYUSUI YANG MEMPUNYAI BAYI $\leq 3$ BULAN DI PRAKTIK MANDIRI BIDAN RISMA DELI SERDANG TAHUN 2019
}

\author{
Rismahara Lubis $^{1 \bowtie}$, Yusniar Siregar ${ }^{2}$ \\ Coreponding author: rismaharalubis@gmail.com \\ 1, 2 Jurusan Kebidanan, Poltekkes Kemenkes Medan, Indonesia
}

Genesis Naskah: Submitted: 10-07-2021, Revised: 16-07-2021, Accepted: 19-07-2021

\begin{abstract}
Abstrak
Air Susu Ibu (ASI) merupakan satu-satunya makanan yang sempurna dan terbaik untuk bayi, karena mengandung unsur gizi yang dibutuhkan oleh bayi untuk pertumbuhan dan perkembangan bayi guna mencapai pertumbuhan dan perkembangan bayi yang optimal. Kenyataan di lapangan masih banyak ibu yang mengalami hambatan/ kendala untuk menyusui bayinya secara ekslusif 6 bulan penuh, padahal menyusui merupakan suatu kondisi yang alamiah/ natural. Salah satu solusi yang dapat membantu mengatasi hambatan dalam pemberian ASI Eksklusif adalah hypnobreastfeeding. Tujuan dilakukan pengabdian masyarakat ini yaitu untuk meningkatkan pengetahuan ibu tentang ASI Eksklusif dan keyakinan ibu untuk dapat memenuhi kecukupan ASI melalui teknik Hypnobreastfeeding pada Bayi sebagai upaya meningkatkan produksi dan pengeluaran ASI. Metode yang digunakan pada kegiatan Pengabdian Masyarakat ini adalah, ceramah, tanya jawab, demonstrasi dan praktek dilakukan oleh instruktur dan penugasan yang dilakukan oleh ibu nifas yang melahirkan di Bidan Praktek Mandiri Risma sebanyak 15 orang. Pelaksanaan Kegiatan Hypnobreastfeeding dilakukan rutin setiap hari sebanyak 5 (lima) kali dalam seminggu dengan mendengarkan rekaman audio Hypnobreastfeeding selama \pm 30 menit, dilakukan secara mandiri oleh peserta. Hasil yang diperoleh memberi manfaat yang sangat besar dirasakan oleh peserta diantaranya mereka merasakan bayi tidak rewel, tidur dengan nyenyak, buang air kecilnya lebih dari 6 kali sehari dan berat badan bayi bertambah. Dari kegiatan ini dapat disimpulkan bahwa melalui kegiatan penyuluhan, demonstrasi cara/ teknik menyusui yang benar dan Hypnobreastfeeding, dapat meningkatkan pengetahuan, keterampilan serta meningkatkan produksi pengeluaran ASI dan memenuhi kecukupan ASI pada ibu yang menyusui bayi yang berusia $\leq 3$ bulan di Praktek Mandiri Bidan Risma.
\end{abstract}

Kata Kunci : Hypnobreastfeeding, Ibu Menyusui, Bayi $\leq 3$ bulan

\section{IMPLEMENTATION OF HYPNOBREASTFEEDING ACTIVITIES IN BREASTFEEDING MOTHERS WHO HAVE BABIES 3 MONTHS IN SELF PRACTICE MIDWIFE RISMA DELI SERDANG IN 2019}

\begin{abstract}
Breast milk is the only perfect and best food for babies, because it contains the nutritional elements needed by babies for infant growth and development in order to achieve optimal baby growth and development. The reality in the field is that there are still many mothers who experience obstacles/constraints to exclusively breastfeed their babies for 6 full months, even though breastfeeding is a natural condition. One solution that can help overcome barriers to exclusive breastfeeding is hypnobreastfeeding. The purpose of this community service is to increase mother's knowledge about exclusive breastfeeding and mother's confidence to be able to meet the adequacy of breastfeeding through Hypnobreastfeeding techniques in infants as an effort to increase milk production and expenditure The methods used in this Community Service activity are lectures, questions and answers, demonstrations and practices carried out by the instructor and assignments carried out by postpartum mothers who gave birth at the Independent Practice Midwife Risma as many as 15 people. The implementation of Hypnobreastfeeding activities is carried out routinely every day 5 (five) times a week by listening to Hypnobreastfeeding audio recordings for \pm 30 minutes, carried out independently by the participants. The results obtained provided enormous benefits for the participants, including they felt that the baby was not fussy, slept soundly, urinated more than 6 times a day and the baby's weight increased. From this activity, it can be concluded that through counseling activities, demonstrations of correct breastfeeding methods/techniques and Hypnobreastfeeding, it can increase knowledge, skills and increase production of breast milk production and fulfill
\end{abstract}


breast milk adequacy in mothers who breastfeed babies aged 3 months at the Independent Practice of Midwife Risma.

Keywords : Hypnobreastfeeding, Breastfeeding Mother, Infant $\leq 3$ months

\section{Pendahuluan}

Air Susu Ibu (ASI) merupakan satu-satunya makanan yang sempurna dan terbaik bagi bayi karena mengandung unsur-unsur gizi yang dibutuhkan oleh bayi untuk pertumbuhan dan perkembangan bayi guna mencapai pertumbuhan dan perkembangan bayi yang optimal. ASI adalah hadiah yang sangat berharga yang dapat diberikan kepada bayi, dalam keadaan miskin mungkin merupakan hadiah satu-satunya, dalam keadaan sakit mungkin merupakan hadiah yang menyelamatkan jiwanya (United Nations Children's Fund dalam Dewi tahun 2013).

Anak yang tidak diberi ASI memiliki risiko yang semakin meningkat untuk sakit, dan dapat menghambat pertumbuhan, bahkan meningkatkan risiko kematian atau cacat. Bayi yang disusui akan menerima perlindungan (kekebalan) terhadap berbagai penyakit melalui air susu ibunya. Jika sebagian besar bayi usia $0-6$ bulan hanya diberikan ASI, artinya hanya ASI dan tidak ada cairan lain atau makanan lainnya, bahkan tidak juga air, maka diperkirakan paling sedikit 1,2 juta nyawa anak dapat diselamatkan setiap tahunnya (Kemenkes RI, 2008).

Berdasarkan data Riset Kesehatan Dasar tahun 2018 menunjukkan bahwa persentase pemberian ASI saja dalam 24 jam terakhir (ASI Ekslusif) adalah 37,3\% dengan capaian tertinggi adalah Propinsi Babel dan terendah adalah NTB. Persentase nasional proses mulai menyusu pada anak umur 0-23, mulai menyusu kurang dari satu jam (IMD) setelah bayi lahir adalah 58,2 \%, dengan persentase tertinggi DKI $(68 \%)$ dan terendah Maluku Utara (35 \%), sementara provinsi Sumatera Utara $40 \%$ yang berada di bawah capaian angka Nasional (Balitbangkes Kemenkes, 2018).

Kenyataan di lapangan masih banyak ibu yang mengalami hambatan/kendala untuk menyusui bayinya secara eksklusif 6 bulan penuh, padahal menyusui merupakan suatu kondisi yang alamiah/natural. Mempersiapkan ibu hamil yang akan menyusui memengaruhi keberhasilan menyusui (Partiwi, 2012). Salah satu solusi yang dapat membantu mengatasi hambatan dalam pemberian ASI Eksklusif adalah hypnobreastfeeding.

Hypnobreastfeeding adalah upaya alami menggunakan energi bawah sadar agar proses menyusui berjalan dengan aman dan lancar, dengan cara memasukkan kalimat-kalimat afirmasi atau sugesti positif disaat ibu dalam keadaan sangat rileks atau sangat berkonsentrasi pada suatu hal/keadaan hipnosissehingga Ibu dapat menghasilkan ASI yang mencukupi untuk kebutuhan tumbuh kembang bayi (Kuswandi, 2013).

Menurut Feher (1989), dengan bimbingan dan panduan $\mathrm{CD}$ relaksasi $5 \mathrm{x}$ dalam seminggu, para Ibu menyusui dapat meningkatkan produksi ASI sebesar $63 \%$. Hasil penelitian Nuratri, dkk (2015) menunjukkan bahwa hypnobreastfeeding diprediksi memengaruhi keberhasilan pemberian ASI Eksklusif sebesar 41\% (R2=0,41). Hasil penelitian Dewi, 2013 bahwa efektivitas gentlebirth terhadap pemberian asi eksklusif menunjukkan $p$ value $<\alpha(0,05)$ yaitu Gentlebirth 
dengan metode Hypnobreastfeeding dan IMD efektif terhadap pemberian Asi Eksklusif. Hasil yang sama juga disampaikan Putriningrum, dkk (2015) bahwa pemberian terapi hypnobreastfeeding berpengaruh pada proses menyusui dengan nilai signifikan 0.002 .

Ada beberapa faktor yang menyebabkan proses laktasi tidak berhasil, diantaranya adalah faktor dari ibu, antara lain adalah faktor fisik yaitu kondisi fisik yang lemah karena kelelahan menjalani proses persalinan, dan juga faktor psikis yaitu kondisi psikologis ibu atau masalah-masalah psikologis ibu yang dapat menghambat kerja oksitosin.

Berdasarkan hal tersebut diatas maka perlu dilakukan kegiatan yang bertujuan untuk meningkatkan kemampuan ibu dalam memberikan ASI secara eksklusif yang dapat memberikan pengaruh positif terhadap proses pertumbuhan dan perkembangan bayi.

Pada tahun 2018 telah dilakukan penelitian tentang Efektifitas Hypnobreastfeeding Pada Ibu Menyusui Terhadap Kecukupan ASI pada Bayi Usia $\leq 3$ Bulan Di Praktik Mandiri Bidan Risma Dan Praktik Mandiri Bidan Sri Armila Deli Serdang Tahun 2018 dan dari hasil penelitian diperoleh bahwa Hypnobreastfeeding efektif untuk memenuhi kecukupan ASI pada bayi usia Hypnobreastfeeding $\leq 3$ bulan di Praktik Mandiri Bidan Risma Dan Praktik Mandiri Bidan Sri Armila Deli Serdang Tahun 2018.

Berdasarkan analisa situasi ibu menyusui dan capaiaan ASI Eksklusif pada latar belakang di atas maka Perlu dilakukan penyuluhan tentang ASI Eksklusif dan aplikasi Hypnobreastfeeding kepada ibu menyusui yang mempunyai bayi usia $\leq 3$ bulan untuk meningkatkan kecukupan ASI.

\section{Metode Pelaksanaan}

Metode yang digunakan pada kegiatan Pengabdian Masyarakat ini adalah, ceramah, tanya jawab, demonstrasi dan praktek dilakukan oleh instruktur. Penugasan (peserta ditugaskan untuk melakukan hypnobreastfeeding secara mandiri dirumah sedikitnya 5 kali seminggu, setiap hari dengan mendengarkan rekaman audio Hypnobreastfeeding \pm 30 menit).

Sarana dan alat yang digunakan: Laptop dan LCD proyektor, speaker audio portable dan Flash disk berisi rekaman panduan relaksasi hypnobreatfeeding. Khalayak sasaran kegiatan hypnobreastfeeding adalah ibu menyusui yang mempunyai bayi $\leq 3$ bulan, yang hanya memberikan ASI saja tanpa cairan dan makanan pendamping lainnya (ASI ekslusif) yang melakukan kunjungan masa nifasnya di Bidan Praktek Mandiri Risma sebanyak 15 orang.

Kegiatan pelaksanaan hypnobreastfeeding pada ibu menyusui yang mempunyai bayi usia $\leq 3$ bulan dilakukan di Bidan Praktek Mandiri Risma Dusun III Krekel Desa Sei Glugur Kecamatan Pancur Batu Kabupaten Deli Serdang $( \pm 10 \mathrm{Km}$ dari Poltekkes Kemenkes Medan). Pelaksanaan kegiatan dilakukan mulai bulan Mei sampai bulan Juli 2019.

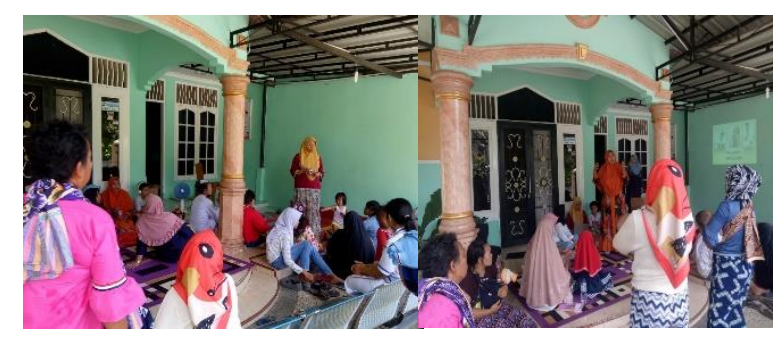

Gambar 1. Penyuluhan dan Demonstrasi Hypnobreastfeeding 


\section{Hasil dan Pembahasan}

Hasil penimbangan terhadap berat badan bayi pada tiap pertemuan dapat dilihat pada tabel di bawah ini:

Tabel 4.1. Berat Badan Bayi sebelum dilakukan Hypnobreastfeeding

\begin{tabular}{|c|c|c|c|}
\hline No & $\begin{array}{c}\text { BB Minggu } \\
\text { Ke-1 }\end{array}$ & $\begin{array}{c}\text { BB Minggu } \\
\text { Ke-2 }\end{array}$ & $\begin{array}{c}\text { BB Minggu } \\
\text { Ke-3 }\end{array}$ \\
\hline 1 & 4500 & 4800 & 5000 \\
\hline 2 & 5000 & 5200 & 5500 \\
\hline 3 & 4700 & 5000 & 5200 \\
\hline 4 & 4300 & 4500 & 4650 \\
\hline 5 & 5500 & 5700 & 5850 \\
\hline 6 & 4500 & 4800 & 4950 \\
\hline 7 & 6000 & 6300 & 6500 \\
\hline 8 & 4500 & 4800 & 5900 \\
\hline 9 & 5500 & 5750 & 6000 \\
\hline 10 & 5400 & 5600 & 5800 \\
\hline 11 & 5000 & 5300 & 5500 \\
\hline 12 & 5300 & 5750 & 5900 \\
\hline 13 & 4800 & 5000 & 5200 \\
\hline 14 & 6000 & 6300 & 6500 \\
\hline 15 & 4900 & 5200 & 5400 \\
\hline
\end{tabular}

Kegiatan Hypnobreastfeeding pada minggu I, dilaksanakan pada tanggal 20 Juli 2019, setelah dilakukan Hypnobreastfeeding selama 1 minggu oleh peserta secara mandiri, dilakukan monitoring dilaksanakan pada tanggal 27 Juli 2019 dengan melakukan penimbangan berat badan bayi. Hasil penimbangan terhadap berat badan bayi dapat diketahui bahwa dari 15 bayi seluruhnya mengalami kenaikan BB lebih dari $125 \mathrm{gr} /$ minggu. Hasil wawancara dengan peserta sebagian besar peserta mengatakan bahwa setelah mereka melakukan kegiatan tersebut bayi-bayi mereka lebih baik "anteng" tidak rewel ataupun cengeng.

Kegiatan melakukan Evaluasi minggu III, dilaksanakan pada tanggal 3 Agustus 2019, dilakukan Hypnobreastfeeding selama 2 minggu oleh peserta secara mandiri, dilakukan evaluasi akhir dengan melakukan penimbangan berat badan bayi. Hasil penimbangan terhadap berat badan bayi dapat diketahui bahwa dari 15 bayi seluruhnya mengalami kenaikan BB lebih dari 125 gr/minggu.

Hasil wawancara dengan peserta sebagian besar peserta mengatakan bahwa setelah mereka melakukan kegiatan tersebut bayi-bayi mereka lebih baik "anteng" tidak rewel ataupun cengeng. Dan berdasarkan jawaban peserta, mereka akan melanjutkan memberikan ASI secara eksklusif sampai bayi berusia 6 bulan. Dan dari evaluasi yang dilakukan terhadap pengetahuan ibu tentang tehnik menyusui yang benar seluruh peserta telah mengetahui tentang tehnik menyusui yang benar dan mampu mempraktekkan tentang teknik menyusui yang benar. Hal ini akan memberikan rasa percaya diri ibu yang tinggi sehingga keberhasilan pencapaian ASI eksklusif dapat tercapai.

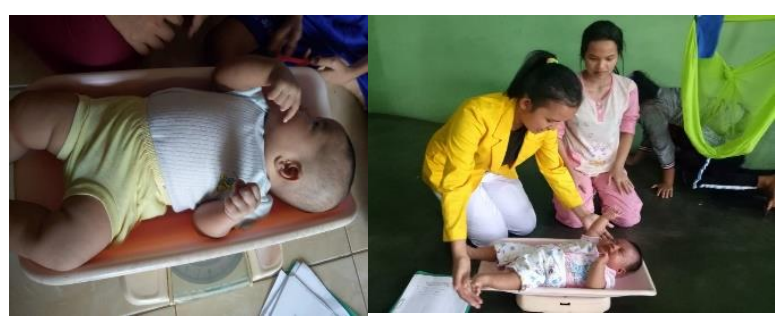

Gambar 2. PengukuranBerat Badan Bayi sebelum dilakukan Hypnobreastfeeding

\section{Pembahasan}

Pelaksanaan kegiatan hypnobreastfeeding dilakukan rutin sebanyak 5 (lima) kali dalam seminggu dengan waktu \pm 30 menit, dilakukan secara mandiri oleh peserta, memberi manfaat yang sangat besar dirasakan oleh peserta 
diantaranya mereka merasakan bayi tidak rewel, tidur dengan nyenyak ,buang air kecilnya lebih dari 6 kali sehari dan terlihat berat badan bayi juga bertambah.

Semakin sering atau rutin ibu melakukan kegiatan Hypnobreastfeeding maka semakin cukup ASI yang ibu miliki karena kegiatan Hypnobreastfeeding mempengaruhi tubuh ibu menjadi lebih rileks, pikiran ibu menjadi lebih tenang. Pikiran yang tenang dan tubuh yang santai akan membantu meningkatkan pengeluaran hormon oksitosin dalam fungsinya memperlancar pengeluaran ASI ibu. Dengan demikian ibu akan memiliki ASI yang cukup dinilai dari frekuensi BAK bayi lebih sering yaitu minimal 6 kali sehari dan kenaikan berat badan bayi.

Menurut hasil penelitian sebelumnya oleh Lubis dan Siregar (2018), diperoleh bahwa Hypnobreastfeeding efektif meningkatkan kecukupan ASI pada bayi usia $\leq 3$ bulan di PMB Risma dan PMB Sri Armila Deli Serdang Tahun 2018.

Hasil penelitian Putriningrum, dkk (2015) juga melaporkan bahwa pemberian terapi hypnobreastfeeding berpengaruh pada proses menyusui dan kenaikan berat badan bayi dengan nilai signifikan 0.002. didapatkan hasil bahwa ibu menyusui dengan hypnobreastfeeding lebih banyak kenaikan berat badan bayinya pada usia 2 dan 3 bulan. Ini menunjukkan bahwa ibu menyusui dengan dilakukannya hypnobreast feeding lebih efektif untuk mencukupi kebutuhan ASI bagi bayinya berdasarkan peningkatan berat badan setiap bulannya yang berarti bahwa peningkatan berat badan bayi perbulan adalah signifikan.

Menurut Soetjiningsih (1997) dalam Frovera (2010), Bayi yang mendapatkan ASI yang cukup tentunya akan lebih senang dan terlihat terlihat sangat puas. Bayi akan dengan mudah mengajak ataupun diajak bermain dengan riang dan juga tertawa. Ada juga tipe bayi akan langsung tertidur dengan lelap jika telah mendapatkan ASI yang cukup. Tapi, jika bayi tidak terasa terpuaskan atau terlihat kurang bergairah dan tidak aktif, maka cek kesehatan dari bayi. Bisa saja bayi sakit sehingga kekurangan nafsu makan.

Untuk mengetahui banyaknya produksi ASI, ada beberapa kriteria yang dapat di pakai sebagai patokan yaitu dengan mengetahui jumlah ASI yang cukup pada bayi antara lain : ASI yang banyak merembes keluar melalui putting, sebelum di susukan payudara terasa tegang, berat badan naik dengan memuaskan sesuai dengan umur, pada umur 5 bulan tercapai 2 x BB lahir. Umur 1 tahun 3x BB lahir, jika ASI cukup, setelah menyusu bayi akan tertidur / tenang selama 3 - 4 jam, bayi kencing lebih sering > 6 kali sehari.

Menurut Depkes Rl (2007), cara yang paling bisa di percaya mengetahui bayi cukup ASI atau tidak, yaitu dengan bertambahnya berat badan bayi, bayi sebaiknya bertambah barat badan paling sedikit 500 gram setiap bulan, atau 125 gram setiap minggu.

Hasil penelitian Putriningrum, dkk (2015) didapatkan hasil bahwa ibu menyusui dengan hypnobreastfeeding lebih banyak kenaikan berat badan bayinya pada usia 2 dan 3 bulan. Ini menunjukkan bahwa ibu menyusui dengan 
dilakukannya hypnobreastfeeding lebih efektif untuk mencukupi kebutuhan ASI bagi bayinya berdasarkan peningkatan berat badan setiap bulannya yang berarti bahwa peningkatan berat badan bayi perbulan adalah signifikan.

\section{Kesimpulan dan Saran}

Melalui Kegiatan penyuluhan dan demonstrasi cara/teknik menyusui yang benar, dapat meningkatkan pengetahuan dan keterampilan ibu-ibu yang menyusui bayi yang berusia $\leq 3$ bulan di Praktek Mandiri Bidan Risma.

Melalui Kegiatan Hypnobreastfeeding pada ibu-ibu yang menyusui bayi berusia $\leq 3$ bulan, dapat meningkatkan produksi dan pengeluaran ASI dan memenuhi kecukupan ASI pada bayi di Praktek Mandiri Bidan Risma.

Kepada Bidan Praktek Mandiri Risma diharapkan dapat terus meningkatkan pelaksanan kegiatan penyuluhan cara menyusui yang benar dan Hypnobreastfeedin kepada setiap ibu menyusui yang datang berkunjung ke BPM.

Melalui hasil kegiatan pengabdian masyarakat ini diharapkan kepada semua fasilitas kesehatan yang melayani pemeriksaan kesehatan ibu dan anak dapat menerapkan kegiatan penyuluhan cara menyusui yang benar dan menginformasikan Hypnobreastfeedin agar capaian pemberian ASI ekslusif tercapai sesuai target Nasional.

\section{Daftar Pustaka}

Aprilla Y. 2014. Gentle Birt, Qonita, Bandung.

Aprilla Y., 2011, Siapa Bilang Melahirkan itu Sakit, Andi Yogyakarta.
Armini, Ni Wayan. 2016. Hypnobreastfeeding Awali Suksesnya ASI Eksklusif. Dalam jurnal Skala Husada Volume 13 nomor 1. Diakses pada tanggal 1 April 2016

Balitbangkes Kemenkes, 2018, Hasil Utama RISKESDAS 2018, Kemenkes RI, Jakarta

Depkes RI. 2007. Pelatihan Konseling Menyusui. Panduan Pelatih. Direktorat Bina Gizi Masyarakat. Jakarta.

Dewi. 2013. Dalam jurnal Kebidanan Vol. 4 No.1 Efektivitas Gentle Birth Terhadap Pemberian ASI Eksklusif. Di akses pada Desember 2013.

Dinkes Provsu. Profil Kesehatan Sumatera Utara, 2015. Diakses Agustus 2016: http://www.depkes.go.id

Feher, S.D.K. 1989. Increasing Breast Milk Production For Premature Infants With a Relaxation/Imagery Audiotape.

Kementerian Kesehatan. 2013. Rencana Aksi Percepatan Penurunan Angka Kematian Ibu di Indonesia. Jakarta : Direktorat Jenderal Bina Gizi dan KIA

Kuswandi, Lanny. 2013. Hypnobirthing A Gentle Way To Give Birth. Pustaka Bunda: Jakarta.

Maryunani A. 2012. Inisiasi Menyusu Dini. ASI Eksklusif dan Manajemen Laktasi. Trans Info Media. Jakarta.

Nuratri A.E. Dasuki D. Wibowo T. 2015. Pengaruh Hypnobreastfeeding Terhadap Keberhasilan Pemberian Asi Eksklusif Di Rumah Sakit Panti Rapih Yogyakarta. UGM. Yogyakarta.

Pratiwi, Nurweni. 2012. Dalam jurnal Faktor-faktor yang Berhubungan Dengan Tidak Dilakukannya Inisiasi Menyusui Dini Oleh Bidan Di Kabupaten Pacitan Tahun 2012. Diakses pada tanggal 12 Juli 2012

Putriningrum R., Khoiriyah A., Umarianti T., 2015, Pengaruh Pengetahuan dan Hypnobreastfeeding pada Ibu Hamil Trimester III terhadap Proses Menyusui, Jurnal Dinamika Kebidanan.

Rusly U. 2008. Inisiasi Menyusu Dini Plus ASI Eksklusif. Jakarta: Pustaka Bunda (Group Puspa Swara). 